Vietnam Journal of Mechanics, VAST, Vol.39, No. 2 (2017), pp. 97-108

DOI:10.15625/0866-7136/8005

\title{
GENERATION OF A DOUBLE-CROWNED INVOLUTE HELICAL GEAR WITH TWIST-FREE TOOTH FLANKS BY A CNC HOBBING MACHINE WITH THREE SYNCHRONOUS AXES
}

\author{
Van-The Tran \\ National Central University, Jungli City, Taiwan \\ Hung Yen University of Technology and Education, Vietnam \\ E-mail: vanct4.hut@gmail.com \\ Received June 31, 2016
}

\begin{abstract}
In the conventional hobbing process, a double-crowned involute helical gear is generated by the hob cutter with parabolic-curve tooth profiles for the cross-profile crowning and varied the center distance between the hob and work gear for the longitudinal crowning. Therefore, to cut a double-crowned helical gear not only requires at least four synchronous axes and hob cutter regrinding (which increases production costs) but also induces twisted tooth flanks on the generated work gear. In this paper, I propose a hobbing method by applying a modified work gear rotation angle that enables double-crowning of involute helical gear's tooth flanks using a standard hob cutter and a computer numerical control (CNC) hobbing machine with only three synchronous axes. The proposed method has also verified by using two computer simulation examples to compare the meshing-conditions, contact ellipses, and transmission errors of the double-crowned gear pairs with that produced by applying the conventional hobbing method. Computer simulation results reveal the advantages of the proposed novel hobbing method.
\end{abstract}

Keywords: Gear hobbing, modified rotation angle, tooth flank twist, contact ellipse, transmission error.

\section{INTRODUCTION}

Involute helical gears are widely used in many industrial applications and doublecrowned involute helical gear surfaces are particularly important for misaligned assembly gear pairs that improve bearing contact and reduce noise. One of the most productive and economical methods for manufacturing such gears is hobbing, which uses two crowning processes to generate double-crowned tooth flanks of an involute helical gear. Conventionally, one crowning process is accomplished in the cross-profile direction by

(C) 2017 Vietnam Academy of Science and Technology 
modifying the hob cutter profile to a parabolic curve and the other is achieved in the longitudinal direction by varying the center distance between the hob and work gear. Using these two processes, however, increases production costs because the standard hob cutter must be reground and the $\mathrm{CNC}$ hobbing machine requires at least four synchronous axes. However, it also induces twisted flanks on the generated work gear's tooth surfaces because of variation in the center distance between the hob and work gear is required during the gear hobbing process. In this paper, therefore, a novel hobbing method for completely double-crowned involute helical gears with a near-zero tooth flank by modifying the work gear rotation angle but without modifying the hob cutter tooth profile is proposed.

The overall geometry, design, and manufacture of a conventional involute helical gear are detailed in two textbooks by Litvin [1], and Litvin and Fuentes [2]. In 2001, Litvin et al. [3] patented a design for helical and spur gear drives with double-crowned pinion tooth surfaces that generate a pre-designed parabolic transmission error function in the meshing process to reduce vibration and noise of a mating gear set. Litvin et al. [4] also proposed a method for modifying the conventional involute helical gear by conjugating a double-crowned gear with a conventional helical involute gear. In 2005, Zanzi and Pedrero [5] applied longitudinal plunging to the manufacture of the doublecrowned pinion of a face gear drive, while Litvin et al. [6] outlined a new topology of modified helical gear tooth surfaces based on profile and longitudinal crownings with nine different zones that generated by a CNC machine with four synchronous axes. This latter is used involute and crowned zones to localize the bearing contact in the presence of misalignments. Just previously, Tseng and Tsay [7] had proposed a mathematical model of a curvilinear tooth gear as a function of hob's design parameters and gear's generation motion parameters based on a CNC hobbing machine. Several years later, Chen et al. [8] developed a mathematical model with a two-parameter equation of meshing for simulating the gear hobbing process. Elsewhere, Lin et al. [9] applied optimization techniques to minimize the surface deviations of the real cut pinion and gear tooth surfaces, and Tang et al. [10] proposed a finite element method (FEM) geometric model for a tooth profile machined by a preground hob. Subsequently, Wang and Fong [11] proposed a novel face-hobbing method to generate spur gears using lengthwise crowning by two head cutters that formed imaginary generating rack with cycloidal lengthwise tooth traces. Winkel [12] then proposed a special profile modification in hob's finishing that produces topological tooth flank modifications with free of twist. More recently, Hsu and Fong [13] patented the design of a longitudinally variable tooth thickness (VTT) hob and a hobbing method with diagonal feed that needs no variation of center distance. Of particular relevance to our verification techniques, Tsay [14], in a much earlier paper, developed a tooth contact analysis computer program for simulating gear meshing and bearing contact, and investigated the influence of gear misalignment on kinematic errors. Shih and Chen [15] then proposed a linear regression methodology for modifying the tooth flank of a gear pair with a high-order correction based on a five-axis CNC gear grinding machine. Lastly, Hsu and $\mathrm{Su}$ [16] investigated the gear tooth surface topologies, contact ellipses, and transmission errors of work gear pairs generated by a modified hob with variable tooth thickness. And Tran et al. [17-19] proposed a novel hobbing 
method to generate anti-twist tooth flanks of the involute helical gear in longitudinal tooth crowning by supplementing an additional rotation angle of work gear during its hobbing process.

This study proposes a novel methodology for obtaining a completely doublecrowned involute helical gear with a near-zero tooth flank twist by modifying the work gear rotation angle without modifying the hob cutter's tooth profile or varying the center distance during the gear hobbing process. In this approach, the hob cutter has two independent movement parameters: the roll ratio movement between the hob and work gear, and the hob's traverse movement. Author has verified proposed method by two numerical examples that compare the double-crowning outcomes with that of the conventional gear hobbing method. With our modification, the tooth flank of the generated work gear surface is crowned in both the cross-profile and longitudinal directions, and is almost twist free.

\section{MODIFIED ROTATION ANGLE OF THE WORK GEAR}

The mathematical models of the standard and double-crowned involute hobs are given in $[18,19]$. Conventionally, a double-crowned involute helical work gear can be achieved through two modifications: making the cross-profile tooth of the hob cutter with a parabolic curve for profile crowning, and making the radial feed movement along the center distance between the hob and work gear with a second-order polynomial for longitudinal crowning. In addition, the diagonal feed is set as a linear function of the hob's traverse feed. These modifications, however, not only increase production costs but also cause a tooth flank twist on the generated work gear. Our proposed method, therefore, breaks with the conventional and VTT double crowning methods by keeping the hob cross-profile as a straight line, maintaining the radial feed as a constant, fixing the hob cutter's tooth thickness, rejecting the diagonal feed, and setting the work gear rotation angle $\phi_{2}\left(\phi_{1}, z_{a}(t)\right)$ as a function of the hob's rotation angle $\phi_{1}$ and the amount of the hob's traverse feed $z_{a}(t)$ (see Eq. (1)) that can be modified by $n$ th-order Taylor polynomials (see Eq. (7)). The rotational relation between the hob and work gear can then be defined as [13]

$$
\phi_{2}\left(\phi_{1}, z_{a}(t)\right)=\frac{N_{1}}{N_{2}} \phi_{1}+e z_{a}(t)
$$

where $N_{1}$ and $N_{2}$ indicate the number of teeth of the hob and work gear, respectively, and $e$ is a coefficient of the linear relation. According to the literature [13], the coefficient $e$ can then be expressed as

$$
e=\frac{\tan \beta_{o 2}+c \sec \beta_{o 2} \sin \beta_{o 1}}{r_{o 2}}
$$

where $\beta_{01}$ and $\beta_{02}$ is the helix angle the hob and work gear, respectively, $c$ is the hob diagonal shift coefficient, and $r_{02}$ radius of the pitch circle.

Because the work gear rotation angle $\phi_{2}\left(\phi_{1}, z_{a}(t)\right)$ is a linear function of the hob's rotation angle $\phi_{1}$ and the traverse movement $z_{a}(t)$ along the axis of work gear, it can be approximated in terms of the rotating angle $\phi_{1}$ and traverse movement $z_{a}(t)$ by nth-order Taylor polynomials, expanded at an arbitrary point $\left(\phi_{1}, z_{a}(t)\right)=\left(\phi_{0}, z_{0}\right)$, as a function 
dependent on two variables. The rotational relation among the work gear, hob, and the Taylor series can then be expressed by

$$
\phi_{2}\left(\phi_{1}, z_{a}(t)\right)=f_{1}\left(\phi_{1}, z_{a}(t)\right)+f_{2}\left(\phi_{1}, z_{a}(t)\right)+\cdots+f_{n}\left(\phi_{1}, z_{a}(t)\right)+R^{n}\left(\phi_{1}, z_{a}(t)\right),
$$

where

$$
\begin{aligned}
f_{1}\left(\phi_{1}, z_{a}(t)\right)= & \phi_{2}\left(\phi_{0}, z_{0}\right)+\phi_{1} \cdot\left(\phi_{2}\right)_{\phi_{1}}^{\prime}\left(\phi_{0}, z_{0}\right)+z_{a}(t) \cdot\left(\phi_{2}\right)_{z_{a}(t)}^{\prime}\left(\phi_{0}, z_{0}\right) \\
\approx & \frac{N_{1}}{N_{2}} \phi_{1}+e z_{a}(t)+\phi_{2}\left(\phi_{0}, z_{0}\right) \\
f_{2}\left(\phi_{1}, z_{a}(t)\right)= & \frac{1}{2 !} \cdot\left[\left(\phi_{1}-\phi_{0}\right)^{2} \cdot\left(\phi_{2}\right)^{\prime \prime}{ }_{\phi_{1}}\left(\phi_{0}, z_{0}\right)\right. \\
& +2 \cdot\left(\phi_{1}-\phi_{0}\right) \cdot\left(z_{a}(t)-z_{0}\right) \cdot\left(\left(\phi_{2}\right)^{\prime}{ }_{\phi_{1}}\right)_{z_{a}(t)}^{\prime}\left(\phi_{0}, z_{0}\right) \\
& \left.+\left(z_{a}(t)-z_{0}\right)^{2} \cdot\left(\phi_{2}\right)^{\prime \prime}{ }_{z_{a}(t)}\left(\phi_{0}, z_{0}\right)\right], \\
f_{n}\left(\phi_{1}, z_{a}(t)\right)= & \frac{1}{n !} \cdot\left[\left(\phi_{1}-\phi_{0}\right)^{n} \cdot\left(\phi_{2}\right)_{\phi_{1}}^{(n)}\left(\phi_{0}, z_{0}\right)\right. \\
& +n \cdot\left(\phi_{1}-\phi_{0}\right)^{n-1}\left(z_{a}(t)-z_{0}\right) \cdot\left(\left(\phi_{2}\right)_{\phi_{1}}^{(n-1)}\right)^{\prime}{ }_{z_{a}(t)}\left(\phi_{0}, z_{0}\right) \\
& +\cdots+n \cdot\left(\phi_{1}-\phi_{0}\right)\left(z_{a}(t)-z_{0}\right)^{n-1} \cdot\left(\left(\phi_{2}\right)^{\prime}{ }_{\phi_{1}}\right)_{z_{a}(t)}^{(n-1)}\left(\phi_{0}, z_{0}\right) \\
& \left.+\left(z_{a}(t)-z_{0}\right)^{n} \cdot\left(\phi_{2}\right)_{z_{a}(t)}^{(n)}\left(\phi_{0}, z_{0}\right)\right]
\end{aligned}
$$

and $R^{n}\left(\phi_{1}, z_{a}(t)\right)$ is the remainder of the Taylor series, which can be omitted for simplicity. By substituting Eqs. (4) to (6) into Eq. (3) and performing certain mathematical operations, the Eq. (3) can then represent in the second-order Taylor polynomials as follows

$$
\phi_{2}\left(\phi_{1}, z_{a}(t)\right)=\frac{N_{1}}{N_{2}} \phi_{1}+e z_{a}(t)+a_{0}+a_{1} \phi_{1}+a_{2} z_{a}(t)+a_{3} \phi_{1}^{2}+a_{4} \phi_{1} z_{a}(t)+a_{5} z_{a}^{2}(t),
$$

where $a_{0}, \ldots, a_{5}$ are coefficients of the proposed modified rotation angle for the involute helical work gear. These coefficients can be obtained directly from Eq. (3) by solving their respective derivatives. The generated tooth surface depends on the motion functions of the rotating angle $\phi_{1}$ and the traverse movement $z_{a}(t)$. The coefficients of Eq. (7) can then be used in the gear hobbing process to generate a double-crowned involute helical gear with twist-free tooth flanks.

\section{SURFACE DEVIATION OF THE DOUBLE-CROWNED INVOLUTE HELICAL GEAR}

The normal deviation of the tooth flank position vectors can be obtained by comparing the double-crowned tooth flank with the uncrowned gear tooth flank. The normal deviations of the double-crowned and uncrowned gear tooth surfaces at their grid points can be obtained by

$$
\delta R_{i j}=\left(\mathbf{R}_{2}-\mathbf{R}_{3}\right) \cdot \mathbf{n}_{3}=\left(x_{2}-x_{3}\right) \cdot n_{x_{3}}+\left(y_{2}-y_{3}\right) \cdot n_{y_{3}}+\left(z_{2}-z_{3}\right) \cdot n_{z_{3}},
$$


where $\mathbf{R}_{2}$ and $\mathbf{R}_{3}$ are the double-crowned and uncrowned work gear surfaces, $\delta R_{i j}$ is the normal deviations of the respective surface grind points, and subscripts $i$ and $j$ are the grid points index. In this paper, the parameters of the grid points on the gear tooth surface are denoted as $i=1,2, \ldots, 9$ and $j=A, B, C, D, E$, as shown in Fig. 1 .

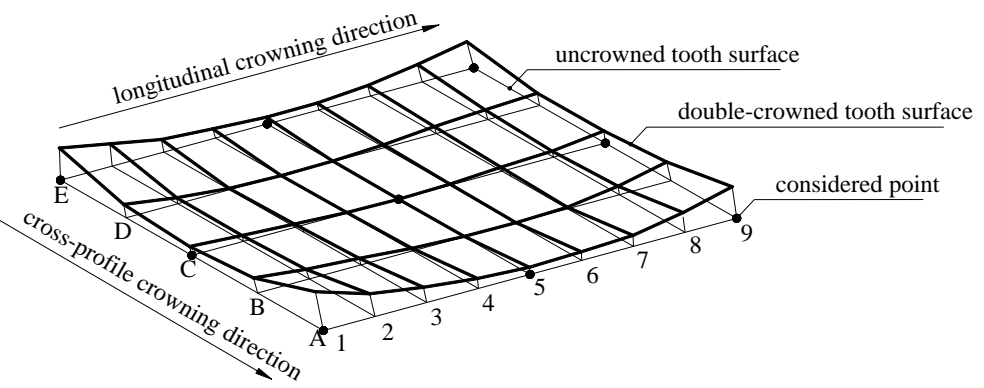

Fig. 1. Normal deviation of position vectors for a double-crowned tooth flank surface

Based on the surface deviation of the points on the double-crowned and uncrowned tooth flanks along the $z$-axis, Eq. (8) can then be represented as

$$
\delta R_{i j}=\left(x_{2}-x_{3}\right) \cdot n_{x_{3}}+\left(y_{2}-y_{3}\right) \cdot n_{y_{3}} .
$$

To compare the level of tooth flank twist in the double-crowned work gear and uncrowned work gear, I propose an index: the longitudinal crowning evenness ratio, $R_{c e}$, defined according to the normal deviation at different selected grid points on each longitude of the work gear surfaces, is calculated using nine different positions along the grid point index: $1 A, 1 C, 1 E, 5 A, 5 C, 5 E, 9 A, 9 C$, and $9 E$. These positions are located on the boundaries and middle normal section of the tooth flank on the work gear surface shown in Fig. 1. follows

The longitudinal crowning evenness ratio for a tooth flank can be calculated as

$R_{c e}=\frac{\min \left(\delta R_{1 A}-\delta R_{5 A}, \delta R_{1 C}-\delta R_{5 C}, \delta R_{1 E}-\delta R_{5 E}, \delta R_{9 A}-\delta R_{5 A}, \delta R_{9 C}-\delta R_{5 C}, \delta R_{9 E}-\delta R_{5 E}\right)}{\max \left(\delta R_{1 A}-\delta R_{5 A}, \delta R_{1 C}-\delta R_{5 C}, \delta R_{1 E}-\delta R_{5 E}, \delta R_{9 A}-\delta R_{5 A}, \delta R_{9 C}-\delta R_{5 C}, \delta R_{9 E}-\delta R_{5 E}\right)}$.

The level of the double-crowned and twist-free tooth flank on the generated work gear is based on the following constrained conditions

$$
R_{c e} \geq R_{c e 0}
$$

and

$$
\Delta \delta R_{\max } \leq \xi_{0}
$$

where $R_{c e 0}$ and $\xi_{0}$ are the longitudinal crowning evenness ratio and tooth flank twist on a designed involute helical gear surface, respectively, and $\Delta \delta R_{\max }$ is the maximum tooth flank twist on the generated double-crowned work gear. In fact, these values depend on the accuracy of the double-crowned tooth flank of the involute helical gear surface design. In this study, the author has chosen these values by $R_{c e 0}=0.85$ and $\xi_{0}=3.0 \mu \mathrm{m}$. 
To obtain a double-crowned and twist free tooth flank on the generated work gear surface, the coefficients of the proposed modified rotation angle in the generation of the double-crowned involute helical gear (Eq. (7)) are determined as indicated in the flow chart shown in Fig. 2. After constructing an algorithm for the uncrowned helical gear tooth surface using 45 sample grid points on the tooth flank shown in Fig. 1, these same 45 grid points are then used to build the proposed double-crowned tooth flank for the work gear surfaces. Next, the data for the parameters corresponding is determined to the uncrowned tooth surface and find a least-squares fit to a list data of $\phi_{1}, z_{a}(t)$, and $\phi_{2}\left(\phi_{1}, z_{a}(t)\right)$ by using Fit Function that is integrated on the commercial software Mathematica (Version 9.0) to predict the estimated coefficients of the proposed modified rotation angle for the work gear during the hobbing process, as expressed in Eq. (7). The tooth flank deviations can then calculate by comparing the double-crowned gear tooth flank surface with the standard gear tooth flank surface. If the constrained conditions expressed in Eqs. (11) and (12) are not satisfied, the estimation and prediction coefficients of the function $\phi_{2}\left(\phi_{1}, z_{a}(t)\right)$ will be repeated again.

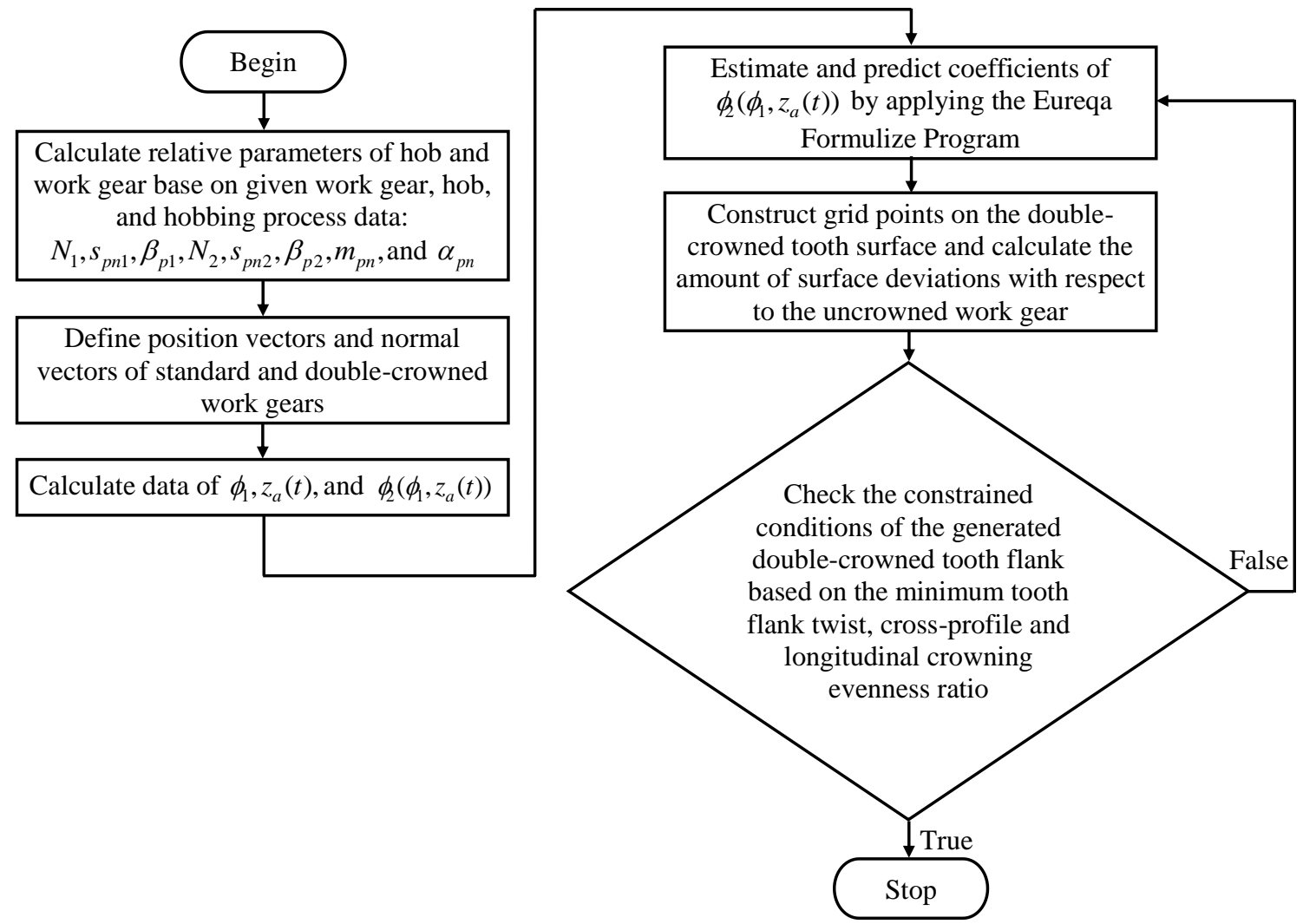

Fig. 2. Flow chart for determining coefficients of the modified rotation angle of the generated work gear 


\section{COMPUTER SIMULATION OF MESHING AND TOOTH CONTACT ANALYSIS}

The conditions of meshing and contact $[2,4]$ are simulated by applying the tooth contact analysis (TCA) to the meshing gear pair, composed of a standard involute helical gear 3 and the proposed double-crowned involute helical pinion 2, whose tooth surface mating equations are represented in the same coordinated system. The coordinate systems for gear meshing are shown in Fig. 3, wherein coordinate systems $S_{2}\left(x_{2}, y_{2}, z_{2}\right)$ and $S_{3}\left(x_{3}, y_{3}, z_{3}\right)$ are rigidly connected to the double-crowned helical pinion 2 and standard involute helical gear 3 , respectively. The auxiliary coordinate systems $S_{h}\left(x_{h}, y_{h}, z_{h}\right)$ and $S_{g}\left(x_{g}, y_{g}, z_{g}\right)$ are rigidly connected to the frame of gear box. By applying the coordinate transformations, the tooth surface equations and surface unit normals of the double-crowned helical pinion 2 and standard involute gear 3 can represent in the fixed coordinate system $S_{h}$. Under the condition of gear meshing, the tooth surfaces of the pinion 2 and gear 3 have a common contact point determinable by the position vectors $\mathbf{R}_{h}^{(2)}$ and $\mathbf{R}_{h}^{(3)}$, as well as a common unit normal vector determinable by the unit normal vectors $\mathbf{n}_{h}^{(2)}$ and $\mathbf{n}_{h}^{(3)}$ at their common contact point, as expressed by Eqs. (13) and (14), respectively

$$
\mathbf{R}_{h}^{(2)}\left(u_{1}, v_{1}, \varphi_{1}, \phi_{1}, z_{a}(t), \phi_{2}\right)=\mathbf{R}_{h}^{(3)}\left(u_{3}, v_{3}, \phi_{3}\right),
$$

and

$$
\mathbf{n}_{h}^{(2)}\left(u_{1}, v_{1}, \varphi_{1}, \phi_{1}, z_{a}(t), \phi_{2}\right)=\mathbf{n}_{h}^{(3)}\left(u_{3}, v_{3}, \phi_{3}\right) .
$$

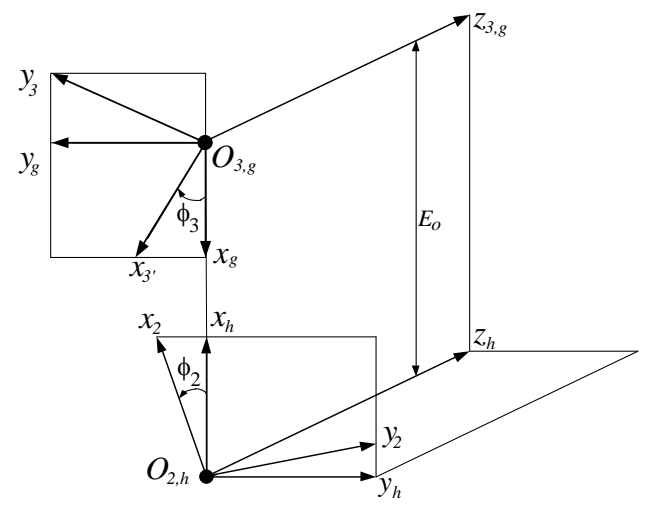

Fig. 3. Simulation of gear meshing pairs with assembly errors

Because Eq. (14) is constrained by the unit normal vector relation $\left|\mathbf{n}_{h}^{(2)}\right|=\left|\mathbf{n}_{h}^{(3)}\right|=$ 1, considering Eqs. (13) and (14) and the three equations of meshing [16] simultaneously yields a system of eight independent equations with nine unknowns: $u_{1}, v_{1}, \varphi_{1}, \phi_{1}, z_{a}(t)$, $\phi_{2}, u_{3}, v_{3}$, and $\phi_{3}$. The variable $\phi_{2}$, however, may also be considered an input variable, meaning that the other eight variables can be solved by eight independent equations with eight unknowns.

Our proposed double crowning method also allows us to obtain a predesigned parabolic function of transmission error $\Delta \phi_{3}\left(\phi_{2}\right)$ induced by assembly errors of the involute 
helical gear set

$$
\Delta \phi_{3}\left(\phi_{2}\right)=\phi_{3}\left(\phi_{2}\right)-\frac{N_{2}}{N_{3}} \phi_{2}=-a_{p r} \phi_{2}^{2}
$$

where $N_{2}$ and $N_{3}$ denote the number of teeth of the double-crowned pinion 2 and standard helical gear 3, respectively, $a_{p r}$ is a parabolic coefficient of the transmission error function, and $\phi_{3}\left(\phi_{2}\right)$ is the gear's rotation angle represented as a function of the pinion's rotation angle $\left(\phi_{2}\right)$.

\section{NUMERICAL EXAMPLES AND DISCUSSION}

\subsection{Example 1}

To validate the proposed double crowning method, the topographies of the doublecrowned work gears generated by the conventional method (Case A) and our proposed method (Case B) are simulated and compared with each other. The basic data for the work gear and hob are listed in Tab. 1; the basic coefficient data for Case A and Case B are given in Tab. 2. Herein, $a$ is the coefficient of center distance variation between the hob and work gear, $b$ is the coefficient of variable tooth thickness and $c$ is the coefficient of the hob's diagonal feed.

Table 1. Basic parameters for the double-crowned helical pinion 2, standard helical gear 3 , and hob

\begin{tabular}{|l|l|l|}
\hline Gear pair data & Gear 2 & Gear 3 \\
\hline Number of teeth $\left(N_{2}\right)$ & 60 & 60 \\
\hline Normal module $\left(m_{p n}\right)$ & 2.5 & 2.5 \\
\hline Normal circular tooth thickness $\left(s_{p n 2}\right)$ & $4.712 \mathrm{~mm}$ & $4.712 \mathrm{~mm}$ \\
\hline Normal pressure angle $\left(\alpha_{p n}\right)$ & $20^{\circ}$ & $20^{\circ}$ \\
\hline Face width & $15.00 \mathrm{~mm}$ & $15.00 \mathrm{~mm}$ \\
\hline Helix angle $\left(\beta_{p 2}\right)$ & $25^{\circ}$ R.H. & $25^{\circ} \mathrm{L} . \mathrm{H}$. \\
\hline Outer diameter & $170.506 \mathrm{~mm}$ & $170.506 \mathrm{~mm}$ \\
\hline Form diameter & $160.648 \mathrm{~mm}$ & $160.648 \mathrm{~mm}$ \\
\hline Hob data & 1 & \\
\hline Number of teeth $\left(N_{1}\right)$ & 1 & \\
\hline Helix angle $\left(\beta_{p 1}\right)$ & $88.388^{\circ} \mathrm{R} . \mathrm{H}$ \\
\hline Normal circular tooth thickness $\left(s_{p n 1}\right)$ & $4.712 \mathrm{~mm}$ \\
\hline Operating data for work gear hobbing & \\
\hline Operating center distance $\left(E_{o}\right)$ & $127.182 \mathrm{~mm}$ \\
\hline Operating crossed angle $\left(\gamma_{o}\right)$ & $113.388^{\circ}$ \\
\hline Operating center distance for gear pairs meshing & $165.507 \mathrm{~mm}$ \\
\hline
\end{tabular}


Table 2. Basic coefficient data and parameters of simulated tooth surface topographies

\begin{tabular}{|c|c|c|c|c|c|}
\hline & $a(\mathrm{~mm}-1)$ & $c$ & $d$ & $\Delta \delta R_{\max }(\mu m)$ & $R_{c e}$ \\
\hline Case A & $0.634 \times 10^{-3}$ & -2.519 & 0.003 & 23.0 & 0.05 \\
\hline Case B & 0 & 0 & 0 & 2.4 & 0.89 \\
\hline
\end{tabular}

The hobbing machine setup data are calculated according to the basic meshing conditions illustrated [1,2], but for the proposed double-crowning method, the work gear rotation angle (expressed in Eq. (7)) must be modified for the gear-hobbing process (see the flow chart of Fig. 2). After calculating the following equation

$$
\begin{aligned}
\phi_{2}\left(\phi_{1}, z_{a}(t)\right)= & 1.205 \times 10^{-6}+16665.543 \times 10^{-6} \phi_{1}+5634.910 \times 10^{-6} z_{a}(t)+ \\
& +4.662 \times 10^{-6} \phi_{1}^{2}+4.706 \times 10^{-6} \phi_{1} z_{a}(t)+5.045 \times 10^{-6} z_{a}^{2}(t) .
\end{aligned}
$$

The normal deviations and simulated tooth surface topographies of the doublecrowned helical gear for the two cases are shown in Tab. 2 and Fig. 4, respectively. Wherein, the averages of the crowning amount of six points $1 A, 1 C, 1 E, 9 A, 9 C$ and $9 E$ on boundary are set as $29.3 \mu \mathrm{m}$ for both two cases. According to Tab. 2 and Fig. 4, these illustrations show a substantial amount of reduction in the maximum tooth flank twists, reducing from $23.0 \mu \mathrm{m}$ (Case A) to a negligible $2.4 \mu \mathrm{m}$ (Case B). Likewise, the longitudinal crowning evenness ratio for the tooth flank surface in Case A $\left(R_{c e}=0.05\right)$ is much smaller than that in Case B $\left(R_{c e}=0.89\right)$. In fact, by substituting the data shown

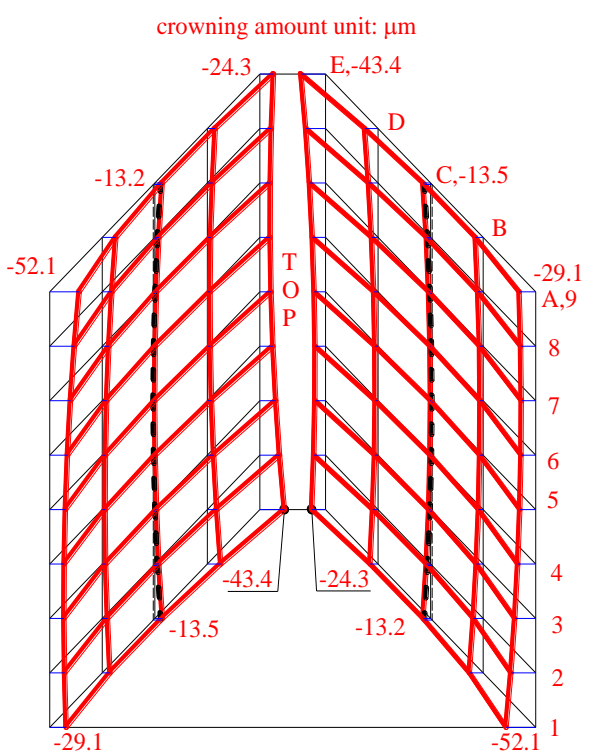

(a) Case A

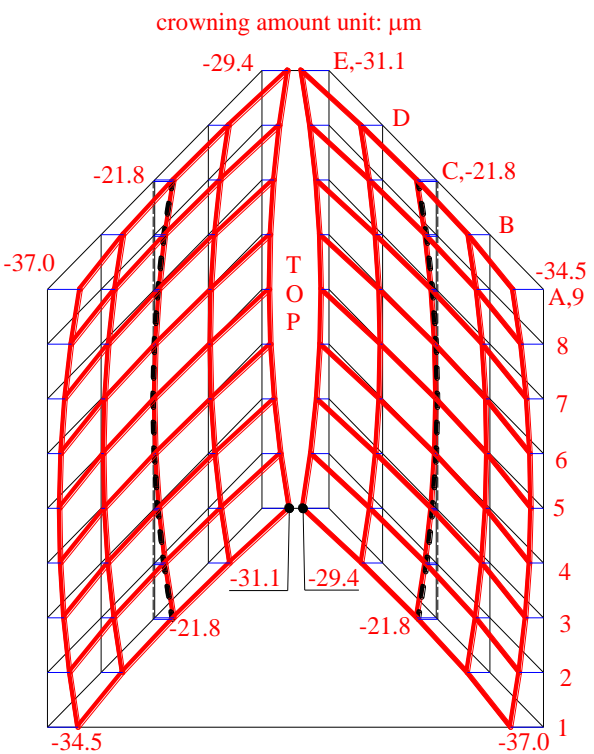

(b) Case B

Fig. 4. Simulated topographies of the double-crowned work gear 
in Fig. 4(b) of the double-crowned involute helical gear in Case B into the constrained conditions of Eqs. (11) and (11) gives

$$
R_{c e}(=0.89) \geq R_{c e 0}(=0.85),
$$

and

$$
\Delta \delta R_{\max }(=2.4) \leq \xi_{0}(=3.0) .
$$

A clear indication that all the design conditions outlined in Eqs. (17) and (18) have been satisfied: the tooth flank of the generated involute helical gear surface is completely double-crowned and almost free of twist. In fact, according to Fig. 4, the tooth flank twist in Case A is much higher than that in Case B.

\subsection{Example 2}

In this example, the contact ellipses and transmission errors of the work gear pairs generated by double crowning with the conventional method (Case A) and proposed modified rotation angle method (Case B) are compared with each other. The work gear pairs mesh under the ideal contact condition (i.e., without assembly errors), and the basic parameters for the hob, the double-crowned pinion 2, and the standard involute helical gear 3 are listed in Tab. 1. The basic coefficients for these two cases are given in Tab. 2 .

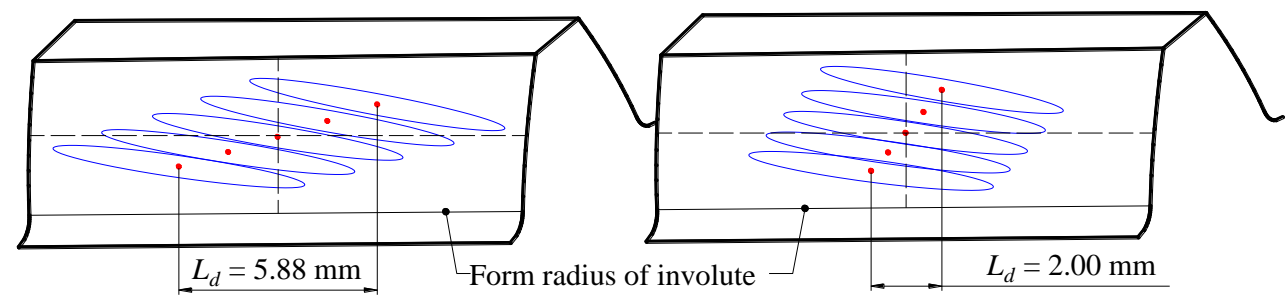

(a) Case $\mathrm{A}$

(b) Case B

Fig. 5. Simulated tooth contact ellipses and contact points of the gear pairs under ideal contact condition

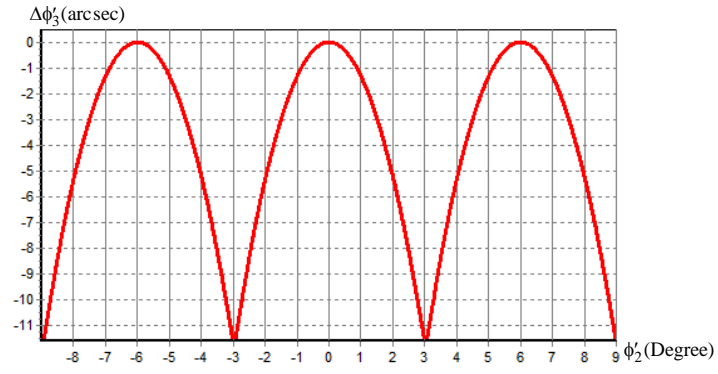

(a) Case A

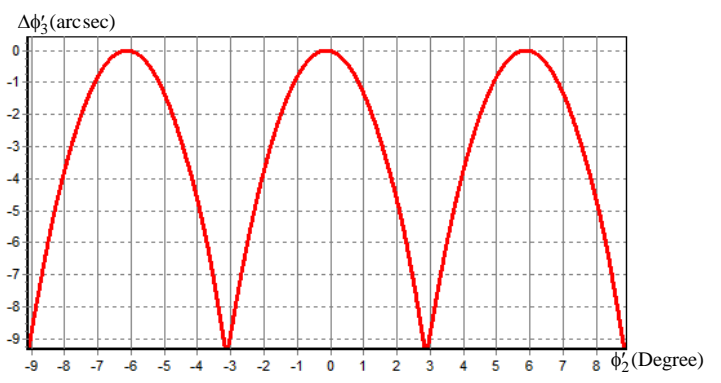

(b) Case B

Fig. 6. Transmission errors of the gear pairs under ideal contact condition 
The tooth contact ellipses, contact points, and transmission errors of a gear pair under the ideal contact condition for Cases A and B are shown in Fig. 5 and Fig. 6, respectively. Here, the contact ellipses for the Case A and B are drawn correspondingly to the rotation angle of pinion $2\left(\phi_{2^{\prime}}=-3.0^{\circ}, \ldots, 3.0^{\circ}\right)$ for Case $\mathrm{A}$ and $\left(\phi_{2^{\prime}}=-3.1^{\circ}, \ldots, 2.9^{\circ}\right)$ Case B, as shown in Fig. 5. The dislocations of the center contact point are nearly equal to zero, but the distribution of contact points in the longitudinal direction are much smaller for Case B $\left(L_{d}=2.00 \mathrm{~mm}\right)$ than for Case A $\left(L_{d}=5.88 \mathrm{~mm}\right)$. Hence, the contact ellipse distribution in Case B is much better than that of Case A, where the contact ellipses and contact points are much more likely to induce edge contact on the gear 3 . In these two cases, the transmission errors are parabolic functions; and the maximum magnitude of transmission error is $\Delta \phi_{3^{\prime}}=11.6 \operatorname{arcsec}$ in Case A and $\Delta \phi_{3^{\prime}}=9.3 \operatorname{arcsec}$ in Case B. Nevertheless, the transmission errors for these two cases are small, as shown in Fig. 6.

\section{CONCLUSIONS}

In this paper, a work gear rotation angle modification is proposed for its hobbing process that enables a double-crowned involute helical gear with a twist-free tooth flank to be generated by a CNC hobbing machine with only three synchronous axes. Based on the simulated numerical examples, the following conclusions are given:

1. When propose modified work gear rotation angle is applied to the gear-hobbing process, the tooth flank of the generated work gear surface is completely crowned in both the cross-profile and longitudinal directions and is nearly free of twist.

2. Simulation and comparison of the topographies of the double-crowned work gear produced by the conventional, VTT, and our propose method clearly show that the tooth flank twist in the first method (Case A) is much greater than that of the second method (Case B).

3. Investigation on the contact characteristics of the double-crowned work gear pairs further reveals that our propose method (Case B) yields much better results in terms of dislocation of the center contact point and distribution of the contact ellipses in the longitudinal direction than those of the conventional method (Case A). It also results in a lower likelihood that the ellipses and contact points will induce edge contact on the generated double-crowned gear.

4. The transmission errors of the propose gear set are in fact a parabolic function and the maximum magnitude of transmission errors in Case B (our propose method) and Case A (conventional) are negligible.

\section{REFERENCES}

[1] F. L. Litvin. Gear geometry and applied theory, pp. 412-468. PTR Prentice Hall, Englewood Cliffs, (1994).

[2] F. L. Litvin and A. Fuentes. Gear geometry and applied theory. Cambridge University Press, (2004). doi:10.1017/cbo9780511547126.

[3] F. L. Litvin, P. H. Peng, S. A. Lagutin, D. P. Townsend, and T. M. Sep. United States Patent No. US 6205879 B1. Technical report, (2001).

[4] F. L. Litvin, A. Fuentes, I. Gonzalez-Perez, L. Carvenali, K. Kawasaki, and R. F. Handschuh. Modified involute helical gears: computerized design, simulation of meshing and stress 
analysis. Computer Methods in Applied Mechanics and Engineering, 192, (33), (2003), pp. 36193655. doi:10.1016/s0045-7825(03)00367-0.

[5] C. Zanzi and J. I. Pedrero. Application of modified geometry of face gear drive. Computer Methods in Applied Mechanics and Engineering, 194, (27), (2005), pp. 3047-3066. doi:10.1016/j.cma.2004.07.022.

[6] F. L. Litvin, I. Gonzalez-Perez, A. Fuentes, K. Hayasaka, and K. Yukishima. Topology of modified surfaces of involute helical gears with line contact developed for improvement of bearing contact, reduction of transmission errors, and stress analysis. Mathematical and Computer Modelling, 42, (9-10), (2005), pp. 1063-1078. doi:10.1016/j.mcm.2004.10.028.

[7] J. T. Tseng and C. B. Tsay. Mathematical model and surface deviation of cylindrical gears with curvilinear shaped teeth cut by a hob cutter. In Proceedings of the ASME 7th Biennial Conference on Engineering Systems Design and Analysis. Manchester, England, (2004), pp. 271-277.

[8] K. H. Chen, C. J. Chen, and Z. H. Fong. Computer simulation for the cutting process of a CNC hobbing machine. In Proceeding of Chinese Society of Mechanism and Machine Theory Conference. Taiwan, (2009), pp. 154-161.

[9] C. Y. Lin, C. B. Tsay, and Z. H. Fong. Computer-aided manufacturing of spiral bevel and hypoid gears by applying optimization techniques. Journal of Materials Processing Technology, 114, (1), (2001), pp. 22-35. doi:10.1016/s0924-0136(01)00734-8.

[10] J. Tang, C. Zhou, and C. Wu. Studies on FEM geometrical model of gear machined by pregrinding hob with protuberance. In ASME 2007 International Design Engineering Technical Conferences and Computers and Information in Engineering Conference. Las Vegas, Nevada, US, (2007), pp. 335-342.

[11] W. S. Wang and Z. H. Fong. A dual face-hobbing method for the cycloidal crowning of spur gears. Mechanism and Machine Theory, 43, (11), (2008), pp. 1416-1430. doi:10.1016/j.mechmachtheory.2007.11.007.

[12] O. Winkel. New developments in gear hobbing. Gear Technology, 3, (4), (2010), pp. 47-55.

[13] R. H. Hsu and Z. H. Fong. Novel variable-tooth-thickness hob for longitudinal crowning in the gear-hobbing process. Mechanism and Machine Theory, 46, (8), (2011), pp. 1084-1096. doi:10.1016/j.mechmachtheory.2011.03.007.

[14] C. B. Tsay. Helical gears with involute shaped teeth: Geometry, computer simulation, tooth contact analysis, and stress analysis. ASME Journal of Mechanical Design, 110, (4), (1988), pp. 482-491. doi:10.1115/1.3258948.

[15] Y. P. Shih and S. D. Chen. A flank correction methodology for a five-axis CNC gear profile grinding machine. Mechanism and Machine Theory, 47, (2012), pp. 31-45. doi:10.1016/j.mechmachtheory.2011.08.009.

[16] R. H. Hsu and H. H. Su. Tooth contact analysis for helical gear pairs generated by a modified hob with variable tooth thickness. Mechanism and Machine Theory, 71, (2014), pp. 40-51. doi:10.1016/j.mechmachtheory.2013.09.001.

[17] V. T. Tran, R. H. Hsu, and C. B. Tsay. Study on the anti-twist helical gear tooth flank with longitudinal tooth crowning. Journal of Mechanical Design, 136, (6), (2014). doi:10.1115/1.4027166.

[18] V. T. Tran, R. H. Hsu, and C. B. Tsay. A novel finish hobbing methodology for longitudinal crowning of a helical gear with twist-free tooth flanks by using dual-lead hob cutters. In ASME 2014 International Mechanical Engineering Congress and Exposition. Quebec, Canada, (2014). doi:10.1115/imece2014-36149.

[19] V. T. Tran, R. H. Hsu, and C. B. Tsay. Tooth contact analysis for a double-crowned involute helical gear with twist-free tooth flanks generated by dual-lead hob cutters. Journal of Mechanical Design, 137, (5), (2015). doi:10.1115/1.4029586. 